\title{
A Prospective Study on Clinical Profile with Special Reference to Etiology, Management and Drug Utilisation Review on Cerebrovascular Accident with Ischemic and Hemorrhagic Stroke
}

\author{
Basheer Sayyed*, Mohammad Akbar Shaik, Sripriya Kamitkar, Muazzamma Shaik, Nagarajan \\ Govindarajan
}

Department of Pharmacy Practice, Dr. K.V. Subba Reddy Institute of Pharmacy, Kurnool, Andhra Pradesh, INDIA.

\begin{abstract}
Background: Stroke is one of the leading causes of death and long-term disability in world. Stroke is an important cause of premature death and disability in low-income and middle-income countries like India, largely driven by demographic changes and enhanced by the increasing prevalence of key modifiable risk factors. Main aim of our study was to assess the clinical profile with special reference to the etiology of the condition, the management and drug utilization review. Methods: A Prospective observational study of 6 months was performed at general medicine department of the tertiary care government general hospital, Kurnool. Total of Hundred Patients aged above 20 years with Cerebrovascular accident with ischemic and hemorrhagic stroke were included following inclusion and exclusion criteria to observe their demographic profile and drug use. The data was analyzed summarized as frequency and percentage by using Microsoft Excel. Results: In our prospective study of hundred patients on cerebrovascular acccident with ischemic and hemorrhagic stroke. We observed males (70\%) were more than females $(30 \%)$. Stratification based on age showed patients admitting to general ward were frequently within the age group of 50-60 and 60-70. Among 100 patients studied, Hypertension (74\%), Diabetes mellitus $(23 \%)$, Smoking (34\%) and alcohol (34\%) were the risk factors respectively. Conclusion: We observed age, hypertension, diabetes mellitus, smoking and alcohol were the major risk factors. We conclude that proper risk factor management and following the guidelines in the treatment reduces the severity, thereby the prognostic factors will be good.
\end{abstract}

Key words: Ischemic Stroke, Hemorrhagic Stroke, Precipitating Factors, WHO Prescribing Indicators, Drug Utilisation Review.

\section{INTRODUCTION}

Stroke is an acute neurologic injury occurring as a result of vascular pathologic processes which manifest either as brain infarction or hemorrhage. Stroke is one of the leading causes of death and long-term disability in India. Stroke is an important cause of premature death and disability in low-income and middle-income countries like India, largely driven by demographic changes and enhanced by the increasing prevalence of key modifiable risk factors. Among all the neurological diseases of adult life, cerebrovascular accidents clearly first in the frequency of importance. Almost fifty percent of neurological diseases in general hospital are due to stroke. Cerebrovascular accident includes ischemic stroke, hemorrhagic stroke and cerebrovascular anomalies such as an intracranial aneurysm, AV malformation and cortical venous thrombosis. Stroke after heart disease is the second most common cause of death among non-communicable disease. ${ }^{1}$ With the introduction of effective treatment for hypertension, there has been a marked reduction in the frequency of stroke. Diabetes mellitus by virtue of its association with microvascular and macrovascular disease is an important risk factor in the genesis of stroke. Most of the diabetic patients with stroke have raised glycosylated
DOI: 10.5530/ijopp.13.1.5

Address for correspondence: Prof. Basheer S, Assistant Professor, Department of Pharmacy Practice, Dr. K.V. Subba Reddy Institute of Pharmacy, Kurnool -518002, Andhra Pradesh, INDIA. Phone no: +91-7799416741 Email Id: sayyedbasheer610@ gmail.com

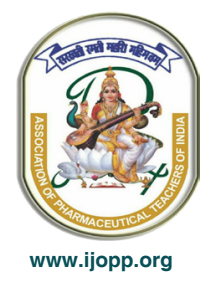


hemoglobin indicating that most of them have uncontrolled diabetes. ${ }^{2}$ Diabetes and stress hyperglycemia have severe strokes resulting in a poor outcome. Stroke is twice more common in diabetes than in non-diabetics. ${ }^{3}$ Hypertension is common in diabetes and accelerates atherosclerosis which promotes intracranial small vessel disease and heart disease leading to lacunar and embolic infarction respectively. There are several risk factors that determine the outcome of a stroke. ${ }^{4}$ The studies related to drug utilization in neurology is limited in India. Drug Utilization Research (DUR) was defined by 'World Health Organization' (WHO) in 1977 as 'Marketing, distribution, prescription and use of drugs in society with special emphasis on resulting medical, social and economic implication. Such studies have to be carried out from time to time. Drug utilization study, especially at the neurology department in India, is very less. Keeping these things in mind we conducted a single centered prospective study in general medicine inpatient department at a tertiary care hospital with objectives to study the profile of patients admitting to the general medicine department, to study the prescriptions based on WHO prescribing indicator and to identify utilization pattern of drugs. A Drug is a complex process. Uncertainties in diagnosis, treatment and medication adherence contribute to wide variations in the way drugs are used for any given condition Drug use evaluation or drug utilization review is an ongoing, authorized and systematic quality improvement process, which is designed to ${ }^{5}$

- Review drug use and/or prescribing patterns.

- Provide feedback of results to clinicians and other relevant groups.

- Develop criteria and standards which describe optimal drug use.

- Promote appropriate drug use through education and other intervention.

\section{MATERIALS AND METHODS}

Study Site: Government General Hospital, Kurnool.

Study Period: The study was carried out for 6 months i.e., from August 2018 to January 2019.

Study Size: 100 patients fit into inclusion criteria from both male and female General Medicine Departments.

Study Design: A Prospective observational study.

\section{Inclusion Criteria}

Patients should be above the age of twenty, have been admitted within twenty-four hours of onset of symptoms, must be diagnosed as a cerebrovascular accident with ischemic or hemorrhagic stroke.

\section{Exclusion criteria}

Pediatric patients and patients presented with illness having stroke-like symptoms from the hospital were excluded.

\section{IRB Approval}

The research protocol was duly approved by IRB of Dr. K. V. Subba Reddy Institute of Pharmacy vide approval number KVSP/IRB 2018-2019/Pharm.D/PROJ/002.

\section{Method of Study}

Selection of the patient was based upon their inclusion criteria and final diagnosis. All the data collected in a patient profile collecting proforma for the study. For drug-drug interactions drug information resources like "Medscape Drug Interaction Checker", "Stockley’s Drug Interactions" were reviewed. Only major and moderate interactions were mentioned which have more probability to appear in patients. The data was analyzed by using Microsoft Office Excel, synthesized the results and interpreted the data in simple frequency and percentages

\section{RESULTS}

\section{Age and Sex incidence}

Our study means that as age advances there is a frequent chance of having a neurological illness which is in conjuncture with other result findings.

\section{Gender Distribution}

In our study of a hundred patients, the majority of them belonged to male sex showing a male preponderance which is commonly seen in most studies which are represented in Table 1 and Figure 1.

\section{Age wise distribution of patients}

The majority $(38 \%)$ of the patients were in the age group of $50-60$ years. as represented in the Table 2 and Figure 2.

\section{Age wise and sex wise distribution of patients}

In our study majority of the patients were among the age group of 50-60 years and 60-70 years with male preponderance than female as such $26(37.1 \%)$ males were of 50-60 years and $16(22.9 \%)$ were of $60-70$ years age group and $12(40 \%)$ females were of 50-60 years and $9(30 \%)$ were of $60-70$ years age group as represented in the Table 3. 


\section{Incidence of risk factors}

\section{Hypertension}

In our study among the hundred patients, we observed $74(74 \%)$ patients were with hypertension and $26(26 \%)$ were without hypertension which was shown in the Table 4. Among the hypertensive patients we had observed 51 were males and 23 were females.

\section{Diabetes Mellitus}

In our study out of a hundred patients, $23(23 \%)$ patients were with diabetes mellitus and $77(77 \%)$ were without diabetes mellitus which was shown in the Table 5. Among the diabetic patients 17 were males and 6 were females.

\section{Smoking}

Excluding females, 34 (34\%) males were smokers and $66(66 \%)$ were nonsmokers was shown in the Table 6.

\section{Alcoholic}

In our study, excluding females 34 (34\%) patients were alcoholic and 66 (66\%) were nonalcoholic among all the 100 patients was shown in the Table 7.

\begin{tabular}{ccc}
\hline Table 1: Gender distribution. & \\
\hline Sex & Frequency $(\boldsymbol{N})$ & Percentage (\%) \\
\hline Male & 70 & 70.0 \\
Female & 30 & 30.0 \\
Total & 100 & 100.0 \\
\hline
\end{tabular}

\begin{tabular}{|c|c|c|}
\hline Age group & Frequency $(N)$ & Percentage (\%) \\
\hline $20-30$ & 4 & 4.0 \\
\hline $30-40$ & 10 & 10.0 \\
\hline $40-50$ & 18 & 18.0 \\
\hline $50-60$ & 38 & 38.0 \\
\hline $60-70$ & 25 & 25.0 \\
\hline $70-80$ & 3 & 3.0 \\
\hline $80-90$ & 2 & 2.0 \\
\hline
\end{tabular}

\section{Table 3: Age wise and sex wise distribution.}

\begin{tabular}{ccc}
\hline Age groups & Male & Female \\
\hline $20-30$ & $01(1.4 \%)$ & $03(10 \%)$ \\
$30-40$ & $09(12.8 \%)$ & $01(3.33 \%)$ \\
$40-50$ & $14(20 \%)$ & $04(13.33 \%)$ \\
$50-60$ & $26(37.1 \%)$ & $12(40 \%)$ \\
$60-70$ & $16(22.9 \%)$ & $09(30 \%)$ \\
$70-80$ & $02(2.9 \%)$ & $01(3.33 \%)$ \\
$80-90$ & $02(2.9 \%)$ & 0 \\
Total & $70(100 \%)$ & $30(100 \%)$ \\
\hline
\end{tabular}

\section{Types of Stroke}

In our study $66(66 \%)$ patients had ischemic stroke among which 45 were male and 21 were female and 32 (32\%) had hemorrhagic stroke among which 21 were males and 11 were females and $2(2 \%)$ were having both ischemic and hemorrhagic stroke which was seen only in males as shown in the Table 8 and Figure 3.

\section{Risk Factors}

In our study of hundred stroke patients, the major etiology was found to be hypertension (74\%) followed by smoking (34\%), alcohol (34\%), diabetes mellitus (23\%), recurrent attacks $(17 \%)$, cardiac diseases $(7 \%)$ and drug noncompliance $(4 \%)$ respectively as shown in the Table 9.

In our study of hundred stroke patients, based on sex wise distribution the frequency of the risk factors were observed as 51 males and 23 females were hypertensive, 17 males and 6 females were diabetic, excluding females, the frequency of both smoking and alcoholics were same i.e., 34, both the sexes with the same frequency 4 were presented with cardiac diseases, 12 males and 5 females had recurrent attacks and 4 males were presented with drug noncompliance as shown in the Table 10 and Figure 4.

\begin{tabular}{ccc}
\hline \multicolumn{3}{c}{ Table 4: Percentage of Hypertensive patients. } \\
& Frequency $(\boldsymbol{N})$ & Percentage (\%) \\
\hline Yes & 74 & 74.0 \\
No & 26 & 26.0 \\
Total & 100 & 100.0 \\
\hline
\end{tabular}

Table 5: Percentage of Diabetic patients.

\begin{tabular}{ccc} 
& Frequency $(\boldsymbol{N})$ & Percentage $(\%)$ \\
\hline Yes & 23 & 23.0 \\
No & 77 & 77.0 \\
Total & 100 & 100.0 \\
\hline
\end{tabular}

Table 6: Percentage of smoking.

\begin{tabular}{ccc} 
& Frequency $(\boldsymbol{N})$ & Percentage (\%) \\
\hline Yes & 34 & 34.0 \\
No & 66 & 66.0 \\
Total & 100 & 100.0 \\
\hline
\end{tabular}

Table 7: Percentage of alcoholic.

\begin{tabular}{ccc} 
& Frequency $(\boldsymbol{N})$ & Percentage (\%) \\
\hline Yes & 34 & 34.0 \\
No & 66 & 66.0 \\
Total & 100 & 100.0 \\
\hline
\end{tabular}




\begin{tabular}{ccccc}
\multicolumn{2}{l}{ Table 8: Types of stroke. } & & \\
Types of stroke & Male & Female & $\begin{array}{c}\text { Frequency } \\
\text { ( })\end{array}$ & $\begin{array}{c}\text { Percentage } \\
\text { (\%) }\end{array}$ \\
\hline $\begin{array}{c}\text { Ischemic Stroke } \\
\text { Hemorrhagic }\end{array}$ & 45 & 21 & 66 & 66.0 \\
$\quad$ Stroke & & 11 & 32 & 32.0 \\
I.S+ H.S & 2 & 0 & 2 & 2.0 \\
Total & 68 & 32 & 100 & 100.0 \\
\hline
\end{tabular}

\section{Table 9: Percentage of risk factors.}

\begin{tabular}{ccc}
\hline Etiology & Frequency $(\boldsymbol{N})$ & Percentage (\%) \\
\hline Hypertension & 74 & 74.0 \\
Diabetes Mellitus & 23 & 23.0 \\
Smoking & 34 & 34.0 \\
Alcohol & 34 & 34.0 \\
Cardiac diseases & 7 & 7.0 \\
Recurrent attacks & 17 & 17.0 \\
Drug noncompliance & 4 & 4.0 \\
\hline
\end{tabular}

\section{Table 10: Risk factors based on sex wise distribution.}

\begin{tabular}{ccc}
\hline Etiology & Male & Female \\
\hline Hypertension & 51 & 23 \\
Diabetes & 17 & 6 \\
Smoking & 34 & 0 \\
Alcohol & 34 & 0 \\
Cardiac diseases & 4 & 4 \\
Recurrent attacks & 12 & 5 \\
Drug noncompliance & 4 & 0 \\
\hline
\end{tabular}

\section{Table 11: WHO Prescribing indicators.}

\begin{tabular}{cc}
\hline WHO Prescribing indicators & Total \\
\hline Number of cases reviewed & 100 \\
Ischemic stroke cases & 67 \\
Hemorrhagic stroke cases & 33 \\
Number of drugs utilized & 782 \\
Percentage of injections utilized & $41.9 \%$ \\
Number of antibiotics & $8.95 \%$ \\
Average number of drugs per prescription & 7.82 \\
\hline
\end{tabular}

\section{Assessment of WHO Prescribing Indicators}

We observed 782 medicines were prescribed in 100 prescriptions. An average number of drugs in prescription was 7.82 , Percentage of injections utilized was found to be $41.9 \%$ (328), Percentage of patients with antibiotics was found to be $8.95 \%$ (70) as represented in Table 11.

\section{Utilization Pattern of Drugs: Classification}

The utilization of various drugs and its classification in both ischemic and hemorrhagic stroke was presented.
Total 22 different drug classes were used with different drugs. Eleven different classes i.e., only half of the classes that were utilised had been accounted for $95 \%$ of drugs utilisation in both which included Gastrointestinal agents $(N=105,13.4 \%)$, Hypolipidemics $(N=100$, $12.7 \%)$, Supplements $(N=98,12.53 \%)$, Antihypertensives $(N=96,12.27 \%)$, Osmotic diuretics $(N=83,10.6 \%)$, Antiplatelet ( $N=70,8.95 \%)$, Antibiotics ( $N=70,8.95 \%)$, Nootropics ( $N=28,3.5 \%)$, Antipyretics and Analgesics $(N=25,3.1)$, Antidiabetics $(N=23,2.94 \%)$ respectively. Very infrequently used a class of drugs included Antidiarrheal (Purgatives), Antiemetics, Antiviral, Laxatives, Bronchodilators, Skeletal muscle relaxants, Corticosteroids, Mucolytics, Hepatoprotectives Table 12.

\section{Utilisation Pattern of Drugs: Nature and Extent of Drug Use}

73 Different drugs were utilised in both ischemic and hemorrhagic stroke of total 100 patients which was as shown in table. Most frequently Hypolipidemic Atorvastatin (12.7\%) was used followed by Osmotic diuretic Mannitol (10.3\%), Aspirin (8.2\%), Pantoprazole (8.2\%), Amlodipine (5.7\%), B-complex (5.1\%), Calcium+VitaminD3 (4.5\%), Ranitidine (4.5\%), Citicholine (2.8\%), Acetaminophen (2.8\%), Phenytoin $(2.3 \%)$, Telmisartan $(2.2 \%)$, Insulin $(2.0 \%)$, Iron Supplements (1.6\%), Metronidazole (1.5\%), Labetalol $(1.5 \%)$, Lorazepam $(1.2 \%)$, Thiamine $(1.1 \%)$, Nimodipine $(0.76 \%)$, Duoiln+Budecort $(0.6 \%)$, Multivitamins $(0.6 \%)$, Cefotaxim (0.5\%), Atenolol (0.5\%), Cefixime $(0.5 \%)$, Nootropil (0.5\%), Clopidogrel $(0.5 \%)$, Ondansetron $(0.5 \%)$, Piperacillin+Tazobactam $(0.35 \%)$, Amoxicillin Clavulanate $(0.3 \%)$, Enoxaparin $(0.3 \%)$, Theophylline ( $0.3 \%)$, Acenocoumarol $(0.2 \%)$, Nifedipine $(0.2 \%)$, Divalproexsodium+Valproic acid $(0.2 \%)$, Metformin+Glimepride (0.2\%), Metoprolol (0.2\%), Metformin (0.2\%), Baclofen (0.2\%), Dexamethasone $(0.2 \%)$, Levitriacetam $(0.2 \%)$, Artesunate $(0.2 \%)$, Doxyxcyline $(0.2 \%)$, Ambroxol (0.2\%), Midazolam $(0.2 \%)$, Atenolol+Amlodipine (0.1\%), Prazosin $(0.1 \%)$, Metformin+Glibenclamide $(0.1 \%)$, Losartan $(0.1 \%)$, Escitalopram+Clonazepam $(0.1 \%)$, Ursodeoxycholic Acid (0.1\%), Salbutamol (0.1\%), Sandostatin(0.1\%), Rifampin+Ethambutol+Isoniazid + Pyrizinamide $(0.1 \%)$, Glibenclamide (0.1\%), Enalapril (0.15), Pyridoxine + Hydrochloride $(0.1 \%)$, Ciproflaxacin $(0.1 \%)$, Streptomycin $(0.1 \%)$, Hydrocortisone $(0.1 \%)$, Dopamine (0.1\%), Acyclovir (0.1\%), Racecadotril (0.1\%), Vitamin C (0.1\%), Potassium Chloride (0.1\%), Tramadol (0.1\%), Methyl Prednisoolone (0.1\%), Pregabalin (0.1\%), Spiranolactone+Torsemide $(0.1 \%)$, Lactulose $(0.1 \%)$ and Gabapentin (0.1\%) Table 13.

Indian Journal of Pharmacy Practice, Vol 13, Issue 1, Jan-Mar, 2020 


\section{Table 12: Utilization pattern of drugs: Classification.}

\begin{tabular}{|c|c|c|c|c|c|}
\hline S. No & Class of drug & I.S & H.S & Frequency $(\mathrm{N})$ & Percentage (\%) \\
\hline 1 & Antiplatelets & 70 & 0 & 70 & 8.95 \\
\hline 2 & Antihypertensives & 42 & 54 & 96 & 12.27 \\
\hline 3 & Anticoagulants & 5 & 0 & 11 & 1.4 \\
\hline 4 & Supplements & 71 & 27 & 98 & 12.53 \\
\hline 5 & Antiepileptics & 22 & 19 & 41 & 5.24 \\
\hline 6 & Gastrointestinal agents & 66 & 39 & 105 & 13.4 \\
\hline 7 & Antibiotics & 45 & 25 & 70 & 8.95 \\
\hline 8 & Nootropics & 18 & 10 & 28 & 3.5 \\
\hline 9 & Hypolipidemic & 68 & 32 & 100 & 12.7 \\
\hline 10 & Antipyretics and analgesics & 18 & 7 & 25 & 3.1 \\
\hline 11 & Antidiabetics & 17 & 6 & 23 & 2.94 \\
\hline 12 & Osmotic diuretics & 50 & 33 & 83 & 10.6 \\
\hline 13 & Laxatives & 2 & 0 & 2 & 0.25 \\
\hline 14 & Bronchodilators & 9 & 0 & 9 & 1.15 \\
\hline 15 & Skeletal muscle relaxants & 2 & 0 & 2 & 0.25 \\
\hline 16 & Corticosteroids & 3 & 1 & 4 & 0.51 \\
\hline 17 & Ionotropic & 1 & 0 & 1 & 0.12 \\
\hline 18 & Antiviral & 1 & 0 & 1 & 0.12 \\
\hline 19 & Antidiarrheal & 8 & 4 & 12 & 1.5 \\
\hline 20 & Mucolytics & 2 & 0 & 2 & 0.25 \\
\hline 21 & Antiemetics & 1 & 3 & 4 & 0.51 \\
\hline \multirow[t]{2}{*}{22} & Hepatoprotectives & 0 & 1 & 1 & 0.12 \\
\hline & Total & 521 & 261 & 782 & 100.36 \\
\hline
\end{tabular}

\section{Table 13: Utilization pattern of drugs: Nature and extent of drug use.}

\begin{tabular}{|c|c|c|c|c|c|}
\hline S.No. & Name of utilized drugs & IS & HS & Frequency & Percent \\
\hline 1 & Mannitol & 48 & 33 & 81 & 10.3 \\
\hline 2 & Aspirin & 65 & 0 & 65 & 8.2 \\
\hline 3 & Atorvastatin & 68 & 32 & 100 & 12.7 \\
\hline 4 & Pantoprazole & 42 & 23 & 65 & 8.2 \\
\hline 5 & Amlodipine & 26 & 20 & 46 & 5.7 \\
\hline 6 & Calcium+Vitamin D3 & 26 & 10 & 36 & 4.5 \\
\hline 7 & Thiamine & 6 & 3 & 9 & 1.1 \\
\hline 8 & Librium & 2 & 2 & 4 & 0.5 \\
\hline 9 & B-Complex & 28 & 12 & 40 & 5.1 \\
\hline 10 & Telmisartan & 4 & 14 & 18 & 2.2 \\
\hline 11 & Human Insulin & 12 & 4 & 16 & 2 \\
\hline 12 & Phenytoin & 8 & 11 & 19 & 2.3 \\
\hline 13 & Iron supplements & 12 & 2 & 14 & 1.6 \\
\hline 14 & $P+G+M$ & 1 & 0 & 1 & 0.1 \\
\hline 15 & Ranitidine & 23 & 14 & 37 & 4.5 \\
\hline 16 & Acetaminophen & 17 & 6 & 23 & 2.8 \\
\hline 17 & Gabapentine & 1 & 0 & 1 & 0.1 \\
\hline 18 & Citicholine & 13 & 9 & 22 & 2.8 \\
\hline 19 & Labetalol & 1 & 11 & 12 & 1.5 \\
\hline 20 & Prazosin & 0 & 1 & 1 & 0.1 \\
\hline 21 & Clopidogrel & 4 & 0 & 4 & 0.5 \\
\hline 22 & Ceftriaxone & 28 & 20 & 48 & 19.7 \\
\hline 23 & Theophylline & 3 & 0 & 3 & 0.3 \\
\hline 24 & Atenolol+Amlodipine & 1 & 0 & 1 & 0.1 \\
\hline
\end{tabular}




\begin{tabular}{|c|c|c|c|c|c|}
\hline & & & & & \\
\hline 25 & Acenocoumarol & 2 & 0 & 2 & 0.2 \\
\hline 26 & Enoxaparin & 3 & 0 & 3 & 0.3 \\
\hline 27 & Metronidazole & 8 & 4 & 12 & 1.5 \\
\hline 28 & Cefotaxime & 2 & 2 & 4 & 0.5 \\
\hline 29 & Atenolol & 2 & 2 & 4 & 0.5 \\
\hline 30 & Metformin+Glibenclamide & 1 & 0 & 1 & 0.1 \\
\hline 31 & Cefixime & 3 & 1 & 4 & 0.5 \\
\hline 32 & Duolin+Budecart & 5 & 0 & 5 & 0.6 \\
\hline 33 & Amoxicilline+Clavulanate & 3 & 0 & 3 & 0.3 \\
\hline 34 & Nootropil & 3 & 1 & 4 & 0.5 \\
\hline 35 & Lorazepam & 6 & 4 & 10 & 1.2 \\
\hline 36 & Nifedipine & 0 & 2 & 2 & 0.2 \\
\hline 37 & Losartan & 1 & 0 & 1 & 0.1 \\
\hline 38 & Escitalopram+Clonazepam & 1 & 0 & 1 & 0.1 \\
\hline 39 & Divalproex sod.+Valproic acid & 2 & 0 & 2 & 0.2 \\
\hline 40 & Multivitamins & 5 & 0 & 5 & 0.6 \\
\hline 41 & Metformin+Glimepiride & 2 & 0 & 2 & 0.2 \\
\hline 42 & Metoprolol & 1 & 1 & 2 & 0.2 \\
\hline 43 & Ursodeoxycholic acid & 0 & 1 & 1 & 0.1 \\
\hline 44 & Metformin & 1 & 1 & 2 & 0.2 \\
\hline 45 & Salbutamol & 1 & 0 & 1 & 0.1 \\
\hline 46 & Sandostatin & 1 & 0 & 1 & 0.1 \\
\hline 47 & Enalapril & 1 & 0 & 1 & 0.1 \\
\hline 48 & Glibenclamide & 0 & 1 & 1 & 0.1 \\
\hline 49 & Baclofen & 2 & 0 & 2 & 0.2 \\
\hline 50 & $R+1+P+E$ & 1 & 0 & 1 & 0.1 \\
\hline 51 & Pyridoxine+Hydrochloride & 1 & 0 & 1 & 0.1 \\
\hline 52 & Dexamethasone & 1 & 1 & 2 & 0.2 \\
\hline 53 & Piperacillin+Tazobactum & 1 & 2 & 3 & 0.3 \\
\hline 54 & Ciprofloxacin & 1 & 0 & 1 & 0.1 \\
\hline 55 & Streptomycin & 1 & 0 & 1 & 0.1 \\
\hline 56 & Hydrocortisone & 1 & 0 & 1 & 0.1 \\
\hline 57 & Levetiracetam & 1 & 1 & 2 & 0.2 \\
\hline 58 & Ondansetron & 1 & 3 & 4 & 0.5 \\
\hline 59 & Dopamine & 1 & 0 & 1 & 0.1 \\
\hline 60 & Artesunate & 2 & 0 & 2 & 0.2 \\
\hline 61 & Doxycycllin & 2 & 0 & 2 & 0.2 \\
\hline 62 & Acyclovir & 1 & 0 & 1 & 0.1 \\
\hline 63 & Racecadotril & 1 & 0 & 1 & 0.1 \\
\hline 64 & Nimodipine & 1 & 5 & 6 & 0.76 \\
\hline 65 & Vitamin-C & 0 & 1 & 1 & 0.1 \\
\hline 66 & Potassium chloride & 1 & 0 & 1 & 0.1 \\
\hline 67 & Tramadol & 1 & 0 & 1 & 0.1 \\
\hline 68 & Methylprednisalone & 1 & 0 & 1 & 0.1 \\
\hline 69 & Ambroxol & 2 & 0 & 2 & 0.2 \\
\hline 70 & Pregabiline & 0 & 1 & 1 & 0.1 \\
\hline 71 & Midazolam & 2 & 0 & 2 & 0.2 \\
\hline 72 & Spiranolactone+Torsemide & 1 & 0 & 1 & 0.1 \\
\hline \multirow[t]{2}{*}{73} & Lactulose & 1 & 0 & 1 & 0.1 \\
\hline & Total & 521 & 261 & 782 & 100.03 \\
\hline
\end{tabular}




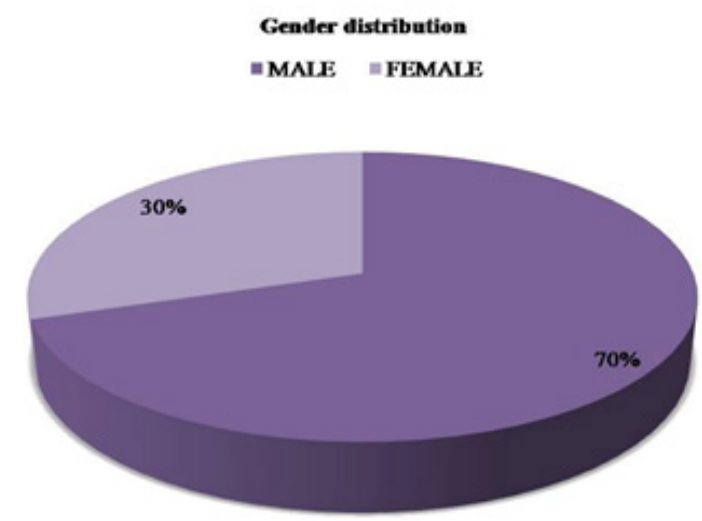

Figure 1: Graphical representation of gender distribution.

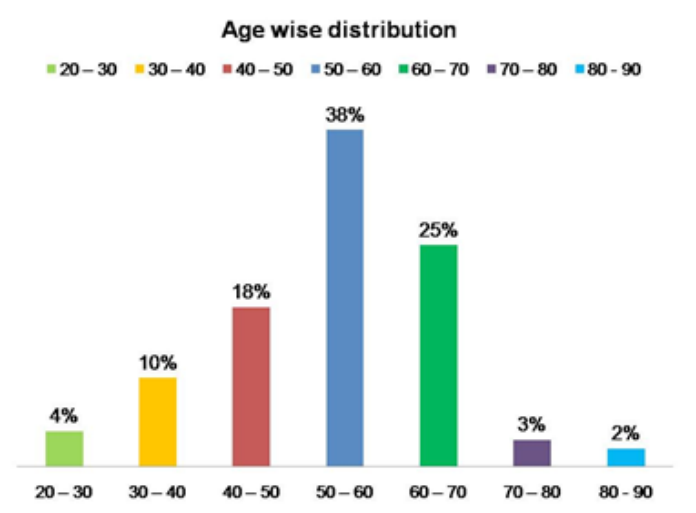

Figure 2: Graphical representation of age wise distribution.

\section{DISCUSSION}

The stroke is considered as an emergency medical condition which is to be treated as early as possible. Other than ischemic and hemorrhagic stroke, there are other conditions like transient ischemic attack and silent ischemic stroke. Our study observed that stroke is being a major burden to neurological illness. In our hospital, the Cerebrovascular accident was a most common diagnosis of stroke but it can vary from region to region and hospitals. Most people with stroke were between 50-60y and 60-70y in age group. Our study also shows that being a male has more chances of stroke. One reason may be due to different-sex steroid hormones, notably estrogens and testosterone. Estrogens have terribly potent effects on endothelial that promote dilation and blood flow whereas testosterone has opposing effect indicating women are protecting with endogenous estrogens. ${ }^{6}$ We already knew that as the number of risk factors increases, the progression and complications of the disease increases. Even in the present study, we found that there were more patients who have involvement of multiple risk factors than single or no risk factors. Proper intervention is to be done assessing risk factors. Measures are to be taken
Types of stroke

$=\mathbf{L} . \mathbf{S}=\mathbf{H . S}=\mathbf{L} . \mathbf{S}+\mathbf{H} . \mathbf{S}$

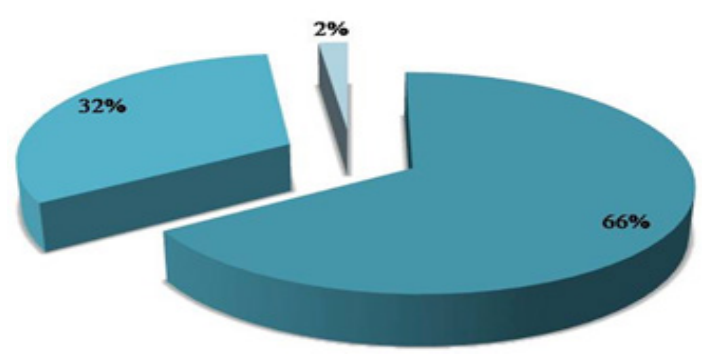

Figure 3: Graphical representation of the percentage of the types of stroke.

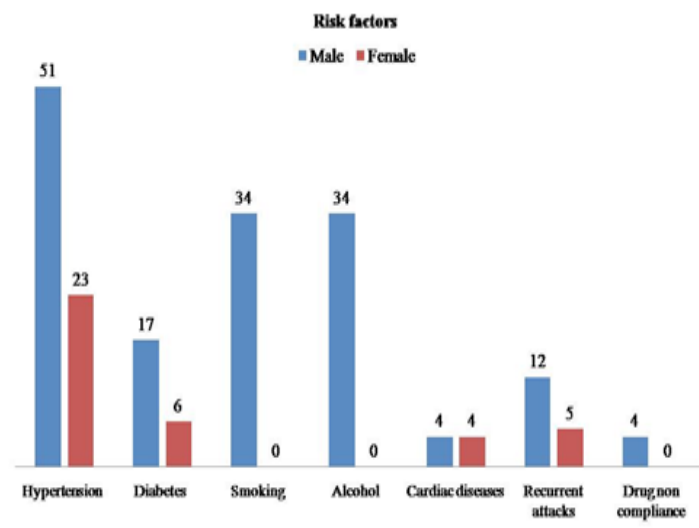

Figure 4: Graphical representation of risk factors based on sex wise distribution.

in order to avoid progression of certain risk factors. Because improper control over stroke leads to disability. The major risk factor in stroke patients in the present study was found to be hypertension (74\%) followed by diabetes $(23 \%)$ and age and the least risk was seen with a past history of coronary artery disease (4\%). The reasons for the progression with these risk factors to the stroke might be due to the change in capillary tone and advances glycation product formation. Drug utilization pattern provides the rationality in drug prescribing and analysis. Prescribing indicators assess the drug use problems in prescriptions from rationality standpoint. ${ }^{7}$ Among different indicators drugs per prescription is high (7.82). This number is high in relation to get drug-drug interactions. In fact, we observed prescription which can theoretically cause effects of serious drug interactions like Ceftriaxone + Enoxaparin, Phenytoin + Nifedipine and Aspirin + Enalapril and moderate drug interactions like Aspirin + Insulin aspartate, Aspirin + Telmisartan, Telmisartan + Atorvastatin, Aspirin + Clopidogrel, Amlodipine + Atenolol, Pantoprazole + Clopidogrel, Phenytoin + Atorvastatin, Phenytoin + Pantoprazole, Calcium + Amlodipine, Metronidazole + Atorvastatin, Amlodipine + Metformin. Close and careful monitoring 
was done to these patients to optimize therapy.

We observed utilization of drugs like Mannitol, Aspirin, Atorvastatin, Multivitamins, Amlodipine, Ceftriaxone, Pantoprazole, Phenytoin, Citicoline, Clopidogrel, Acetaminophen, Metronidazole. Apart from these drugs, we observed the use of a combination of drugs like Atenolol + Amlodipine, Metformin + Glibenclamide, Metformin + Glimepiride, Calcium + Vitamin D3, Spironolactone + Torsemide, Clopidogrel + Aspirin. Antihypertensives like $\beta$-blockers, Diuretics, Calcium channel blockers, $\alpha+\beta$ blockers, Angiotensin II receptor blockers were used to reduce target BP for these patients. It shows the fact that antihypertensive's were frequently used agents for stroke patients, along with Antihypertensives, Antiplatelets, Anticoagulants, Dyslipidemics, Nootropics, Multivitamins, Antidiabetics were also prescribed. Drugs to be administered for conditions occurring after the initial event (epilepsy, depression, anxiety and dementia) like Antiepileptics Antipsychotics, CNS stimulants were also prescribed to the patients. ${ }^{8-10}$ Our results are in conjuncture to these findings. In our Study, we have observed that Clopidogrel was given only to the patients with cardiac disorders and to the patients who are allergic to Aspirin. Primary management of stroke includes Antiplatelet therapy with Aspirin, together with Clopidogrel used in the management of stroke and in patients with past history of cardiac disorders and Clopidogrel, Statin therapy and blood pressure management. Primary prevention interventions are expected to target behavioral modifications such as to reduced smoking, alcohol, salt consumption patterns and increased physical activity. Increasing fruit and vegetable consumption is considered to reduce the risk of stroke by $6 \% .{ }^{11}$ Secondary prevention is through pharmacological therapy. Tertiary prevention is attributed to maintaining their ability to carry out daily activities if they receive rehabilitation services at home. Stroke rehabilitation is expected to begin as soon as possible after the person has a stroke and continue for as long as it is clinically appropriate. ${ }^{8}$ Treatment pattern of illness other than stroke involved specific pharmacological agents like Antiepileptics like Levetiracetam, Gabapentin, Phenytoin, Lorazepam and Antipsychotics like Escitalopram and Clonazepam for Seizures related to Stroke or Epilepsy. Steroids like Dexamethasone and Methyl Prednisolone were used primarily. Other agents were used for symptomatic treatment like Antibiotics, Alkaliser's, Supplements, Antipyretics, Laxatives, Sedative-Hypnotics, Antidepressants, Antidiabetics.

\section{CONCLUSION}

In most of the cases, drug utilization review was done effectively, an average number of drugs per prescription with different types of drug classes used in both ischemic and hemorrhagic stroke were found accordingly. Most of the patients attending the department of general medicine with ischemic and hemorrhagic stroke were above the age of fifty and geriatric patients. Stroke occupies topmost burdens. We observed high drugs per prescription for stroke cases mostly generic drugs were used based on the socioeconomic status of the patient. In our study, we observed age, Hypertension (74\%), Diabetes mellitus (23\%), Smoking (34\%) and Alcohol (34\%) were the major risk factors. Various type of drugs were used depending on the diseased condition illness of the patient. In our study most commonly Antiplatelets, Statins, Osmotic Diuretics like Aspirin, Atorvastatin and Mannitol were respectively utilized based on the types of stroke.

A primary prevention strategy to reduce highly prevalent neurological cases like stroke is needed. Finally, we conclude that proper risk factor management and following the guidelines in the treatment reduces the severity, thereby the prognostic factors will be good. Early identifications of risk factors and pattern of therapy play a crucial role in qualitative patient care such that can reduce the recurrent attacks of the stroke.

\section{ACKNOWLEDGEMENT}

It is a great pleasance to convey our gratification and sincere thanks to Dr. K. Narasimhulu, M.D. (Gen.Med.), DTCD., Professor and HOD, Department of General Medicine, Govt. General Hospital and Dr. M. Ramanjulu, M.S., M.Ch, (Neurosurgery), HOD, Department of Neurosurgery, Govt. General Hospital for their guidance, supervision and support during the study. We take this opportunity to acknowledge the management and principal of Dr. K. V. Subba Reddy Institute of Pharmacy, Kurnool for providing necessary facilities and timely help to complete our work.

\section{ABBREVATIONS}

BP: Blood Pressure; DUR: Drug Utilization Review; H.S: Hemorrhagic Stroke; IH: Ischemic Stroke; WHO: World Health Organization.

\section{SUMMARY}

- The study was carried out in an attempt to find out the major risk factors and to evaluate the quality of drugs prescribing at Tertiary care Hospital. The study showed an active involvement of clinical pharmacists in different wards of General Medicine Department.

- The major risk factor found in our study was hypertension followed by diabetes mellitusin order 
to control high blood pressure patient have to follow regular physical activity, maintaining a healthy body weight, reducing salt (sodium chloride) intake, consuming a diet that emphasizes fruits, vegetables and low-fat dairy products and that is reduced in fat and cholesterol. Male patients were more prone to be affected with the condition due to smoking and consumption of alcohol which have to be avoided.

- Stroke is a time-sensitive condition regardless of whether it is ischemic or hemorrhagic. although Pharmacotherapeutic treatment options are limited, they have been shown to reduce the complications associated with stroke. Pharmacotherapeutic treatment options also reduce the risk of recurrent stroke

\section{REFERENCES}

1. Stroke management. Recent concepts. Medicine Update. 2016;113(06):480-86.

2. Harrison's. Principle of Internal Medicine. $16^{\text {th }}$ ed.,2161.

3. Adams R. Principles of Neurology. $6^{\text {th }}$ ed.

4. Clinical Outcome in Ischemic Stroke Patients with Hyperglycemia [Pg]. The Tamilnadu Dr. MGR Medical University; 2018.

5. Nyfort-Hansen KG. A text book of clinical pharmacy practice. 2nd ed. University press; 2007.

6. Cheryl DBM. Sex differences in stroke, epidemiology, clinical presentation, medical care and outcomes. Lancet Neurol. 2008;7(10):915-26.

7. Abel ATL. Drug utilisation study of stroke and other patients admitted to general ward of neurology unit at quaternary care private hospital. International Journal of Current Pharmaceutical Research. 2019;9(4):23-2.

8. Mathews GCS. Post-stroke seizures. Arch Neurol. 2002;59(2):194-202.

9. Corman CK. Blood pressure management in acute stroke: Comparison of current guidelines with prescribing patterns. Canadian Journal of Neurological Sciences. 2002;29(9):125-31.

10. Lin YJP. The prescribing patterns of antithrombotic agents for prevention of recurrent ischemic stroke. Acta Neurol Taiwan. 2009;18(2):98-103.

11. Andhuvan G, Ayyappan P, Sahana C, Poovizhi S, Sivasakthi K. Knowledge of modifiable risk factors of heart disease among patients with cardiovascular ris. Asian J Pharm Clin Rres. 2017;10:99-102. 